\title{
Thermal Stress Analysis of Tractor Clutch Pressure Plate *
}

\author{
HU Dong-fang ${ }^{1, \mathrm{a}}, \mathrm{HE}$ Min-lu ${ }^{1, \mathrm{~b}}, \mathrm{ZHAO}$ Yan $^{2, \mathrm{c}}$ \\ ${ }^{1}$ School of Mechatronics Engineering, Henan University of Science and Technology, Luoyang 471003, China \\ ${ }^{2}$ LandGlass Technology Co., Ltd, Luoyang 471003, China \\ E-mail: ${ }^{a} h d f @$ haust.edu.cn, ${ }^{b}$ hmljdi@163.com, ${ }^{c h l x c-2009 @ 163 . c o m ~}$
}

\begin{abstract}
Thermal ablation, thermal cracking and other problems often appear in pressure plate of tractor clutch. To solve the problems above, the completed platen solid model of the फ280 clutch pressure plate was established in Solidworks software. Then the finite element model was established for analysis to calculate the thermal stress coupling analysis the heat and stress conditions of the pressure plate. The structure of the pressure plate was improved by changing the level surface to slope shape and increasing friction surface taper to 1 degree. After optimization the pressure plate, the temperature peak is decreased $0.12 \%$, stress peak is decreased $11.96 \%$, and axial deformation is decreased $6.9 \%$.
\end{abstract}

Keywords—clutch; pressure plate; thermal stress; finite element analysis

\section{INTRODUCTION}

Pressure plate is one of the main parts of the clutch. The high temperature generated in the clutch contact process causes thermal deformation and has a great impact on the performance of the clutch. Some scholars have come to some conclusions and proposed some improvement program through a series of tests and finite element analysis ${ }^{[1-2]}$. But the study of tractor double-acting clutch pressure plate is still relatively little or none. Therefore, on the basis of previous studies, the author get to the stress and temperature and deformation distribution by simulating the pressure plate conditions, which based on ABAQUS finite element analysis . According to the analysis result, the structure of the pressure plate is improved and a more reasonable pressure plate design is obtained.

\section{FINITE ELEMENT ANALYSIS OF PRESSURE PLATE}

\section{A. Modeling and parameter acquisition}

Three dimensional model of $\varphi 280$ clutch pressure plate is established in the Solidworks. The finite element model is established by the interface of software ABAQUS and Solidworks. Then tetrahedron elements of Couple Temperature-Displacement is used meshing the model. The element size is $2 \mathrm{~mm}$. The total number of elements is 651,230 and the total number of nodes is 124,895 .

Pressure plate material is HT250. Analysis use $\mathrm{mm} /$ tonne / $\mathrm{s}$ as units. Material parameters: density is $7.28 \times 10^{-9} \mathrm{~T} / \mathrm{mm}^{3}$,

Project supported by the National Natural Science Foundation (No. 51475142) and the Key Technology R \&D Program of Henan Province (No. 13A520232) and the Major and previous pre-research project of Henan University of Science and Technology (No. 2011CX016). conductivity is $45 \mathrm{~mJ} /(\mathrm{s} \cdot \mathrm{mm} \cdot \mathrm{K})$, Young's modulus is $1.38 \times 10^{5} \mathrm{~N} / \mathrm{mm}^{2}$, Poisson's ratio is 0.3 , specific heat is $5.1 \times 10^{8} \mathrm{~mJ} /(\mathrm{T} \cdot \mathrm{K})$, thermal expansion is $8.2 \times 10^{-6} / \mathrm{K}$.

\section{B. Working-process simulation}

The working condition is the general conditions in this paper. During the engaging process of clutch, slipping friction work is translated into heat between the pressure plate and the driven disc. Slipping friction work in general load conditions can be calculated according to the following formula.

$$
W=\frac{\omega_{\varepsilon}}{2\left(1-\frac{1}{\beta}\right)\left(\frac{1}{I_{1}}+\frac{1}{I_{2}}\right)}
$$

$\omega_{\varepsilon}$ is the angular velocity of the engine during tractor starting; $\beta$ is reserve coefficient, $\beta=2.31 ; I_{1}$ is the moment of inertial for equivalent rotation quality of the engine, $I_{1}=1.76 \times 10^{3} \mathrm{t} / \mathrm{mm}^{2} ; I_{2}$ is the moment of inertial of the clutch shaft transformed by the equivalent rotary quality of the tractor, $\mathrm{I}_{2}=0.64 \times 10^{3} \mathrm{t} / \mathrm{mm}^{2}$. The slipping friction work can be calculated, $\mathrm{W}=2.1962 \times 10^{7} \mathrm{~mJ}$.

According to experience, the combination time is $2.05 \mathrm{~s}$, and the separation time is $1 \mathrm{~s}$. In this paper, the coupled thermal stress analysis of pressure plate is obtained by direct coupling method. Simulate combination condition and set the step combination for $2.05 \mathrm{~s}$; Simulate the separation condition and set the step separation for $1 \mathrm{~s}$.

\section{Boundary conditions}

Since being pressed by disc spring pressure, the suppressed part of the clutch pressure plate can be dealt as rigid constraints, namely the axial displacement is zero. The 3 holes on the outer edge which was mounted clutch driving strap does not exist relative displacement in the circumference of a circle tangent direction that can be dealt as rigid constraints. So the radial displacement is zero.

Initialization temperature is as follows:

$$
T(x, y, z, t)=T_{0}
$$

$x, y$ and $z$ are the coordinate values of the test point; $t$ is time; $\mathrm{T}_{0}$ is environment temperature. $\mathrm{T}_{0}=30^{\circ} \mathrm{C}$.

Convective heat transfer refers to the heat exchange due to temperature difference between fluid and wall when the fluid relatively moved contact with the solid wall whose temperature is not the same. Rising temperature caused by slipping, and then convection with the surrounding air, which 
is said convective heat transfer coefficient. The convective heat transfer coefficient of the pressure plate is calculated by formula (3) ${ }^{[3]}$ :

$$
h=0.023 \frac{\lambda}{D} \operatorname{Re}^{0.8} \operatorname{Pr}^{0.4}
$$

$\lambda$ is the heat conduction coefficient of air, D is feature size, Pr is Prandtl number, Re is Reynolds number. From formula (3), the convective heat transfer coefficient is 0.0145 $\mathrm{mJ} /\left(\mathrm{mm}^{2} \cdot \mathrm{s} \cdot{ }^{\circ} \mathrm{C}\right)$ when it is $30^{\circ} \mathrm{C}$, and the convective heat transfer coefficient is $0.013 \mathrm{~mJ} /\left(\mathrm{mm}^{2} \cdot \mathrm{s} \cdot{ }^{\circ} \mathrm{C}\right)$ when it is $80^{\circ} \mathrm{C}$. The convective heat transfer coefficient between the two values is obtained by the method of linear interpolation. There is no convective heat transfer in step combination, because of the closely combination between the pressure plate and the friction plate; Put the convective heat transfer boundary conditions to the friction surface when the pressure plate and friction plate in the separation condition.

Heat flux is the rate of heat energy transfer in per unit surface through a given surface. Heat flux density is the heat rate per unit area. The heat generated by slipping is all absorbed by the pressure plate and friction plate. According to the formula provided by literature [3], the heat flux at the time $t$ from the center of the pressure plate is as follows:

$$
q=\frac{3 W r}{\pi t_{0}\left(R^{3}-r^{3}\right)}\left(1-\frac{t}{t_{0}}\right)
$$

$\mathrm{W}$ is the friction work which obtained in formula (1); $\mathrm{R}$ is the outer diameter and $\mathrm{r}$ is the inner diameter of pressure plate. Bring W $=2.1962 \times 10^{7} \mathrm{~mJ} \mathrm{t}_{0}=2.05 \mathrm{~s}, \mathrm{R}=141.5 \mathrm{~mm}, \mathrm{r}=$ $82.5 \mathrm{~mm}$ into formula (4), the heat flux generated between the pressure plate and friction plate is obtained, $\mathrm{q}=4.508 \mathrm{r}$ (1$0.488 \mathrm{t})$.

It is necessary to introduce the concept of heat distribution coefficient to calculate the heat flux. It represents a matching parameter of frictional heat between the pressure plate and the friction plate of clutch. The formula is provided in literature [4].

$$
k=\frac{q_{y}}{q_{m}}=\left(\frac{\lambda_{y} c_{y} \rho_{y}}{\lambda_{m} c_{m} \rho_{m}}\right)^{0.5}
$$

$\lambda$ is conductivity, $\mathrm{c}$ is specific heat, $\rho$ is density. Bring the material parameters into the formula (5), it can be calculated $\mathrm{k}=11.6$. The study uses a single-plate clutch friction, so the heat flux is distributed on the pressure plate can be calculated by following formula ${ }^{[5]}$.

$$
q_{y}=\frac{1}{2} \cdot \frac{k}{k+1} q
$$

Since the thermal conductivity of the friction plate material is not fine. Most of the heat is absorbed by the pressure plate. Bring $\mathrm{k}$ into the formula (6) and the heat flux of pressure platen can be obtained, $\mathrm{q}_{\mathrm{y}}=4.234 \mathrm{r}(1-0.488 \mathrm{t})$.

\section{RESULTS OF FINITE ELEMENT SIMULATION ANALYSIS}

\section{A. Analysis of the temperature distribution}

As Fig.1 shows, the highest temperature occurs at $1.089 \mathrm{~s}$ near the outer edge of the pressure plate. It's node ID is 5394 and the maximum temperature is $65.36^{\circ} \mathrm{C}$. The maximum temperature is $57.52{ }^{\circ} \mathrm{C}$ at $2.05 \mathrm{~s}$ when slipping end. The maximum temperature of pressure plate appears before the end of combination. Because the angular velocity of pressure plate and friction plate is consistent and the friction work is gradually reduced at the end of the friction; The heat generated by the friction is less than the heat of conduction and thermal convection ${ }^{[6]}$. The maximum temperature rises to $35.34^{\circ} \mathrm{C}$ in the whole friction process.

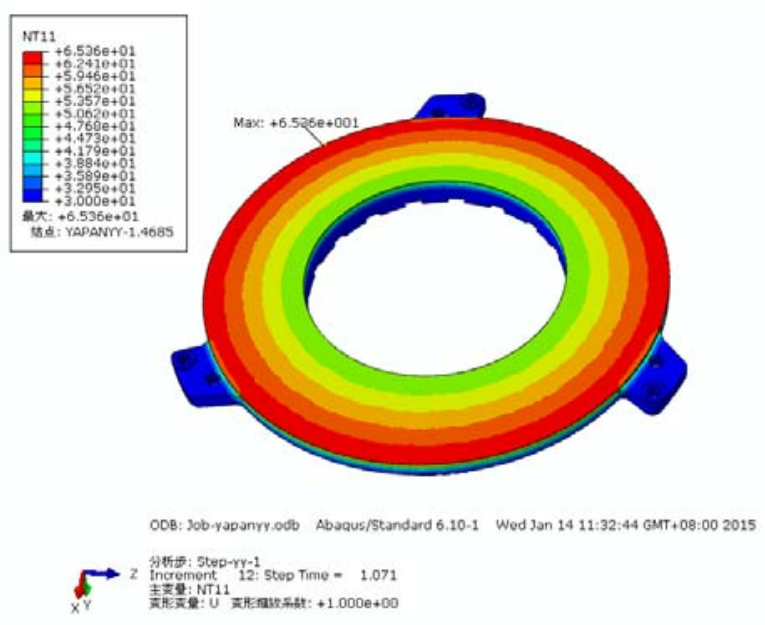

Fig.1 Peak temperature nephogram

In the process of the combination of the pressure plate, temperature changing trends on the radial friction surface are the same, which the temperature sharply rises and decline slowly. As shown in Fig.2 (a), there are the temperature change curves of 7 radial nodes on the friction surface of the pressure plate. At the beginning of combination, friction work increases sharply and the temperature rise sharply; But in the end, friction work has been greatly reduced, the heat generated by friction is less than the heat of conduction and thermal convection; The clutch enter separate state and temperature is further reduced. The friction surface as a instantaneous heat source, the speed is proportional to the radius. The temperature increases with the radius. The Fig.2 (b) is the temperature curves of 7 axial nodes axially on outer end face of the pressure plate. In the axial direction, the peak temperature is gradually reduced away from the slide friction surface. Temperature changing trend of the node near the friction surface is similar to friction surface, which temperature rises rapidly at first, then decline slowly. However, temperatures of the nodes far from the friction surface are approximately monotonically increasing trend. 


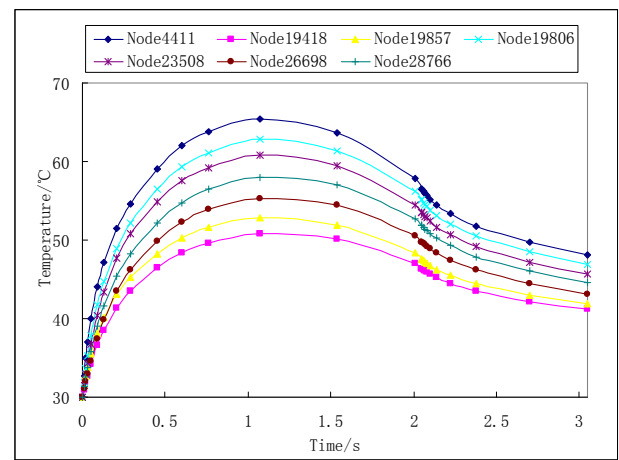

(a) Radial nodes

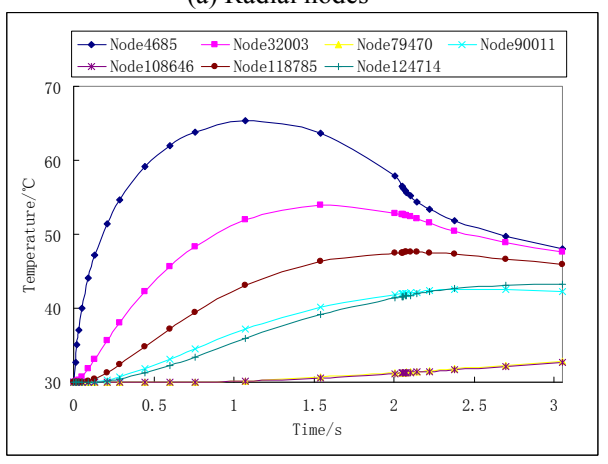

(b) Axial node

Fig. 2 Temperature variation curves

The maximum temperature occurs when the clutch is combined $1.089 \mathrm{~s}$, and the peak stress occurs only when the clutch is combined $1.539 \mathrm{~s}$. It suggests that thermal stress caused by temperature variations. The maximum of Von Mise equivalent stress occurs near the region of the mounting hole. It's stress peak reached $144.6 \mathrm{MPa}$. The frictional heat is transferred to the lug and the convective heat transfer through the lug, which lead to a lower temperature in this area. The area is the highest temperature region, and the maximum temperature gradient, the stress concentration, the maximum of Von Mise all occur here.

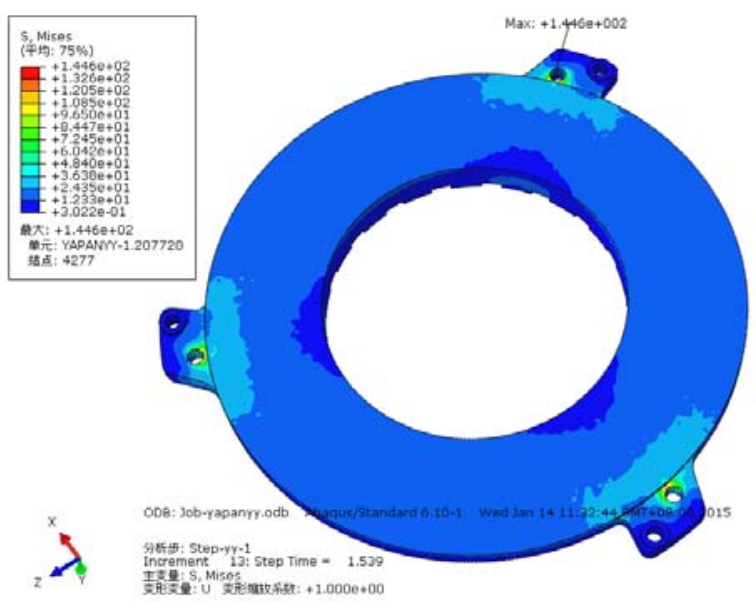

Fig.3 Peak stress nephogram

\section{B. Deformation analysis}

As shown in Fig.4, the pressure plate deformation shows the radial expansion and axial warp. Friction surface temperature along the part of the outside is high. The deformation is the largest at the outer edge where absence constraints. The value is up to $0.03784 \mathrm{~mm}$. Because of the constraints in lugs place, the expansion of the pressure plate in the radial deformation is controlled effectively. The large temperature gradient in axial direction leads to uneven warpage in outer edge of clutch, which will exacerbate the partial wear of sliding surface.

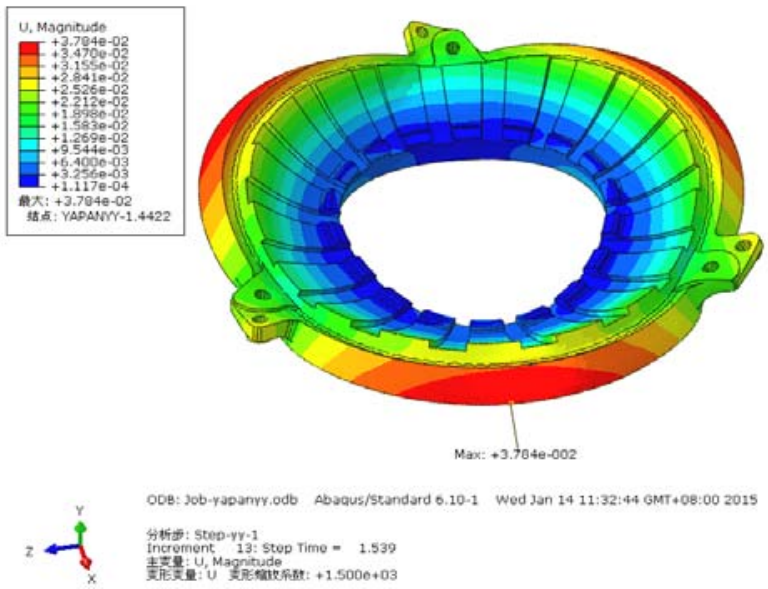

Fig.4 Deformation nephogram

\section{STRUCTURE IMPROVEMENT}

According to analysis, noticeable temperature rise, concentrated stress distribution, and seriously axial warp of the pressure plate are exist in the process of combination of the clutch. The structure of the pressure plate is improved from the angle of reduce the effect of thermal stress. The original level is changed to the surface slope shape, which play a role in reinforcing rib. The axial plate warping phenomenon has been improved to some extent, as shown in Fig.6. Original structure of friction surface taper is increased to 1 degree. The working process of the clutch friction area will be increased. Then the axial deformation of pressure plate caused by the friction surface is increased. The structure is compared in Fig.5.
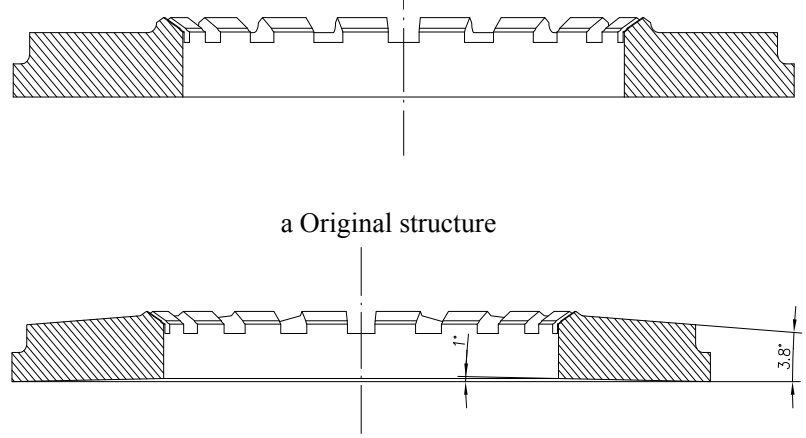

b The improved structure

Fig.5 Comparison of original structure and the improved structure 
To test the effect of the improved structure, thermal stress analysis of the new structure is conducted with the same conditions. The improved structure analysis results are shown in Fig.6, Fig.7 and Fig.8. The new structure should be superior to the original structure by contrast. The contrast results are shown in Tab.1. The peak temperature of the improved structure is reduced by $0.12 \%$, the peak stress is reduced by $11.96 \%$, and the axial deformation is reduced by $6.9 \%$.

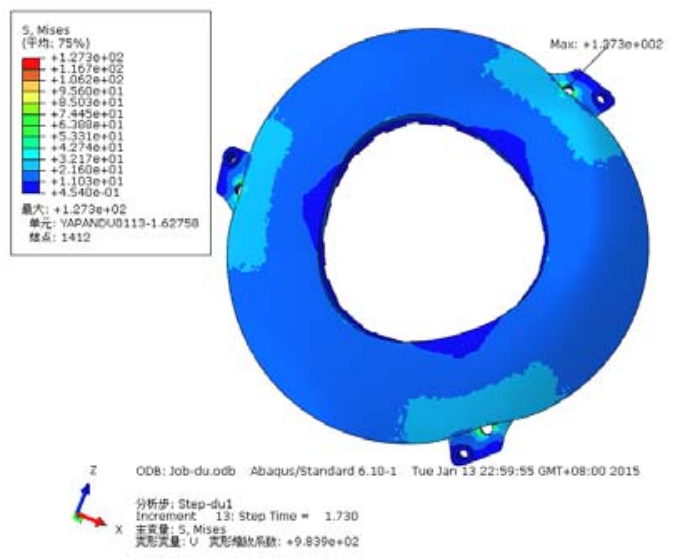

Fig.6 Peak stress nephogram of the improved structure

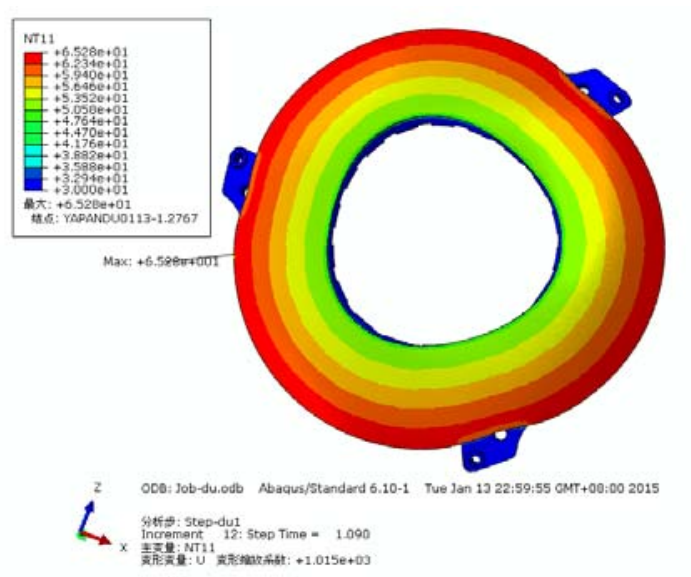

Fig.7 Peak temperature nephogram of the improved structure

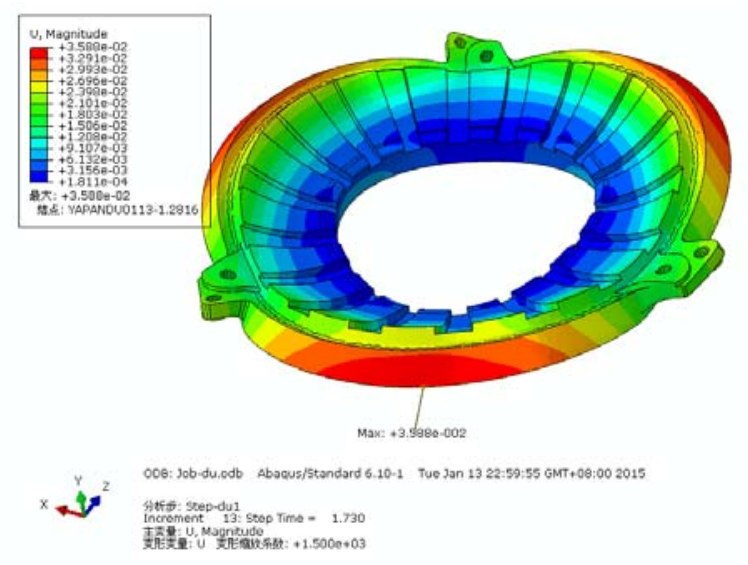

Fig.8 The peak displacement nephogram
Tab.1 Contrast results of the original structure and the improved structure

\begin{tabular}{ccccc}
\hline & $\begin{array}{c}\text { Temperatu } \\
\text { re/ }{ }^{\circ} \mathrm{C}\end{array}$ & $\begin{array}{c}\text { Stress } \\
/ \mathbf{M p a}\end{array}$ & $\begin{array}{c}\text { Total } \\
\text { deformation } \\
/ \mathbf{m m}\end{array}$ & $\begin{array}{c}\text { Axial } \\
\text { Deformation } \\
/ \mathbf{m m}\end{array}$ \\
\hline $\begin{array}{c}\text { Original } \\
\text { structure }\end{array}$ & 65.36 & 144.6 & 0.03784 & 0.03353 \\
$\begin{array}{c}\text { Improved } \\
\text { structure }\end{array}$ & 65.28 & 127.3 & 0.03588 & 0.03120 \\
$\begin{array}{c}\text { Discrepanc } \\
\text { y for }\end{array}$ & $0.12 \%$ & 11.96 & $5.20 \%$ & $6.9 \%$ \\
percentage & & $\%$ & & \\
\hline
\end{tabular}

\section{EXPERIMENT}

The operation performance of the clutch and the strength of the assembly durability experiment are verified in experiment. The test results are shown in table 2 .

Tab. 2 Results of assembly durability test

\begin{tabular}{ccccc}
\hline \multirow{2}{*}{ Item } & Technical & \multicolumn{3}{c}{ Result of inspection } \\
\cline { 3 - 5 } & requirement & $\begin{array}{c}\text { Original } \\
\text { design }\end{array}$ & $\begin{array}{c}\text { Postoptima } \\
\text { lity }\end{array}$ & $\begin{array}{c}\text { Percenta } \\
\text { ge }\end{array}$ \\
\hline & Wear loss of & Side A & & \\
& $\begin{array}{c}\text { one side for } \\
\text { friction }\end{array}$ & 0.69 & Side A 0.67 & $2.9 \%$ \\
Assembly & plate $\leq 0.8 \mathrm{~mm}$ & 0.42 & Side B 0.41 & $2.38 \%$ \\
durability & Wear loss of & & & \\
test(25000 & pressure & 0.07 & 0.06 & $14.29 \%$ \\
times) & No damage to & No & & \\
& parts & damage & No damage & \\
\hline
\end{tabular}

\section{CONCLUSION}

According to analysis the pressure plate of tractor clutch, some results are obtained. The peak temperature is $65.19{ }^{\circ} \mathrm{C}$, and the temperature distribution is uneven. Temperature at outer diameter is higher than inner diameter. Stress peak lags behind the temperature peak and occurs near the mounting holes. The peak stress is up to $111.8 \mathrm{Mpa}$. The displacement deformation is $0.03022 \mathrm{~mm}$. Phenomena of stress concentration and warping deformation are obviously. The structure of the pressure plate has been changed. The original level on the surface is changed to a slope shape, and the original friction surface taper is increased by 1 degree. After the adjustment, the wear loss of side $\mathrm{A}$ and $\mathrm{B}$ of friction plate has decreased by $2.9 \%$ and $2.38 \%$, and the wear loss of pressure plate has decreased by $14.29 \%$. The overall performance of the pressure plate has been improved, which improve the service life of the clutch assembly.

\section{References}

[1] Zhu Maotao, Zhang Tieshan, Measurement of Working Temperature Variation in Automobile Clutch Pressure Plate Surface, Journal of Jiangsu University of Science and Technology, 1996, 17(2): 32-36.

[2] Zhang Fan, Bao Jiping, Finite Element Analysis and Improvement on the Thermal Stress of the Truck Clutch Pressure Plate, Forestry achinery \&Woodworking Equipment. 2011, 39(4): 23-26. 
[3] Yang Shiming, Ta Shuangying, Heat Transfer[M], Beijing: Science Press, 2012

[4] Liu Xuelai, Zhu maotao, Research of Coupling Heat Load Characteristic Analysis and Improvement of Cluch Pressure Plate. Mechanical Transmission, 2014, 38(5): 128-131.
[5] Guo Xiaowen, Zhang liping, Thermal condition analysis and improvement measures of bus friction clutch. Mechanical \& Electrical Technology, 2014(1): 77-80.

[6] Gao Xiang, Xu Yang, Thermal-Machanical Coupling of Clutch Pressure Plate in Start Condition, Journal of Chongqing Jiaotong University (Nature Science), 2014, 33(3): 149-154. 